\title{
AUTOGENOUS ARTERIOVENOUS ELBOW FISTULA FOR HAEMODIALYSIS AND UPPER EXTREMITY ISCHEMIA
}

\author{
Petr Bachleda ${ }^{\mathrm{a} *}$, Petr Utikal ${ }^{\mathrm{a}}$, Zdenek Kojecky $^{\mathrm{a}}$, Petr Drac ${ }^{\mathrm{a}}$, Martin Köcher ${ }^{\mathrm{b}}$, \\ Marie Cerna ${ }^{\mathrm{b}}$, Josef Zadrazil ${ }^{\mathrm{c}}$ \\ a $2^{\text {nd }}$ Department of Surgery, University Hospital Olomouc, Czech Republic \\ ${ }^{b}$ Department of Radiology, University Hospital Olomouc \\ ${ }^{c} 3^{\text {rd }}$ Department of Internal Medicine, University Hospital Olomouc \\ e-mail:petr.bachleda@fnol.cz
}

Received: April 17, 2007; Accepted:April 28, 2007

Key words: Haemodialysis/Arteriovenous elbow fistula/Steal syndrome

Background: The autogenous brachiocefalic or brachiobasilic arteriovenous elbow fistula is not considered to be only the secondary haemodialysis access. In patients with an unsuitable forearm vessel bundle, it is indicated as primary access and it is the method preferred to the fistula creation using a vascular prosthesis. Its rather rare complication is the development of upper extremity ischemia.

Aim: To summarise current knowledge of this fistula type and its associated complications

Methods: Review of the literature.

Results: The creation and maturation of the fistula and occurrence of the steal syndrome is influenced by a number of factors. The analysis and awareness of such factors will provide for creation of a suitable fistula as well as for timely complication diagnostics and treatment.

Conclusions: The autogenous elbow fistula utilising the brachial artery and the cephalic or basilic vein in the upper extremity represents a high-quality haemodialysis access. Its potential complication is the occurrence of the steal syndrome. Its occurrence and manifestations do not constitute indications for ligation of the access. The gathered information shows that a suitable surgical procedure can help meet the basic rule for haemodialysis access - resolving the ischemia and maintaining the access.

\section{INTRODUCTION}

The creation of a quality arteriovenous (AV) fistula for haemodialysis is dependent on a relatively healthy and undamaged arterial and subcutaneous venous bed. The standard primary AV fistula in Europe is the BresciaCimino fistula ${ }^{1}$ or a modification thereof.

The autogenous AV fistula in elbow, which utilises the rich subcutaneous venous bed, is mainly considered the "secondary" access after having exhausted all the possibilities of fistula creation at the more distal level ${ }^{2}$. Today older, polymorbid patients are dialysed with lower quality distal forearm vascular bundle, unsuitable for AV fistula creation, and elbow fistula becomes the primary access. The cephalic or basilic veins are arterialised via the brachial artery.

In 1970 Cascardo et al. ${ }^{3}$ published their experience in creating elbow AV fistulas for low-quality forearm arterial bed. The use of the basilic vein is described by Dagher ${ }^{4}$. Use of the perforating vein for anastomosis was published by $\mathrm{Gracz}^{5} \cdot 10-25 \%$ of cases of the brachiocephalic and brachiobasilic AV fistulas show steal syndrome presentations.

\section{METHODS}

Using the Pubmed database, relevant publications were found on creation of the autogenous arteriovenous fistulas for haemodialysis in the elbow with a focus on the occurrence of the steal syndrome and upper extremity ischemia.

\section{RESULTS}

The method of primary arteriovenous fistula creation is different in Europe and in the U.S.A. Primary autogenous fistula is created in $80 \%$ of patients in Europe compared to $24 \%$ in the U.S. ${ }^{6}$. In the early 1990 s, the method of choice in the U.S. was the AV fistula using an ePTFE graft, which ensured high blood flow rates of the fistula? The complications associated with these fistulas are wellknown and are predominantly of stenotic and thrombotic nature $^{8-10}$. In the mid-1990s, the situation was reviewed in the U.S., following the DOQI recommendation, and revival of the autogenous fistulas took place due to less proneness to stenoses, thromboses and infectious complications in comparison with the grafts. It was recommended that 
at least $50 \%$ of the fistulas created was autogenous ${ }^{2,11}$. A summary of the observations of both access types in the U.S. shows that both fistula types have a comparable operating duration, with the advantage of autogenous fistulas being the lower number of post-maturity complications and fistula interventions. Maintaining the graft operable requires a higher number of procedures such as angioplasty, thrombectomy and surgical revision. Grafts also demonstrate a higher occurrence rate of infectious complications. The creation of the autogenous AV fistula is associated with early post-insertion complications and the necessary maturation of the fistula. Its subsequent operation is typically of a long-term nature with a low complication rate ${ }^{8,12,13}$. This opinion can be agreed with. It should be mentioned that the autogenous fistula has always been considered the gold standard in Europe.

The age of patient included in the chronic dialysis programme is increasing and so is mainly the number of patients with atherosclerotic and diabetic complications. The creation of the AV fistula at the wrist level is often impossible in such patients. This is due to the sclerotic arterial bed of the forearm, often combined with a poor subcutaneous venous bed. The method of choice in the creation of the autogenous arteriovenous fistula is the elbow fistula, which involves arterialisation of the subcutaneous venous bed of the basilic or cephalic veins in the arm by means of anastomosis to the brachial artery. The autogenous elbow fistula is currently the access used for the creation of up to $45 \%$ of primary autogenous fistulas for haemodialysis in Europe. Its creation is technically easy but it is necessary to consider all possible complications which make it difficult or prevent its application and which require further surgical procedures. In terms of utility and complication occurrence, the results are very good $^{13-17}$. This fistula type involves well-known disadvantages and complications. Arterialisation of the basilic vein is often accompanied by concurrent or subsequent basilic vein anteposition because, in its physiological course, it is placed subfascially in the proximal $2 / 3$ of the $\operatorname{arm}^{16,18}$. The adverse complication of these fistula types is the possible gradual development of the steal syndrome with upper extremity ischemia.

Despite great care in the creation of arteriovenous anastomosis of the fistula within the diameter of $7 \mathrm{~mm}$, there is always the risk of development of a hyperfunctional fistula with steal syndrome and hand ischemia ${ }^{19}$. Under suitable anatomical conditions, the prevention can involve performance of elbow fistula more distally on the radial or ulnar artery just under the brachial artery branching using the v. mediana antebrachii ${ }^{20}$. U.S. literature recognises the steal syndrome and deals with it mainly in fistulas performed using the ePTFE graft $^{21,22}$. The steal syndrome shows early manifestations in fistulas performed with a graft as opposed to their later manifestation in autogenous fistulas in connection with fistula development ${ }^{23}$.

Diabetes mellitus is considered a risk factor for the occurrence of this complication ${ }^{11,16,24-28}$. However, some authors do not agree ${ }^{29}$. Other risk factors include the use of brachial artery ${ }^{30,31}$, age over $60^{30}$, female gender ${ }^{26,31}$ and lupus $^{26}$. In terms of the steal syndrome occurrence, the brachiocephalic fistula is a risk factor as opposed to the radiocephalic fistula or to the application of the loop using a vascular prosthesis ${ }^{24}$. In advanced ischemic symptoms with finger gangrene, the basic factor is the atherosclero$\mathrm{sis}^{26,27}$. Since providing access for haemodialysis is a priority, the performance of the fistula in the elbow is preferred in diabetic patients to the radiocephalic forearm fistula, which is patent yet unsuitable for cannulation ${ }^{17}$.

The actual occurrence of the steal syndrome demonstrations after elbow fistula performance between the brachial artery and the cephalic or basilic veins is difficult to assess because published reports usually do not specify the performance type with regard to fistula complications ${ }^{14,32,33}$. The steal syndrome fistula has an asymptomatic form, the so-called "physiological steal" which occurs in $80 \%$ of the patients, and a symptomatic form. The physiological steal is a demonstrable drop in blood pressure at the periphery and is compensated by the arterial collateral circulation and vasodilation. If these mechanisms fail, the symptomatic form occurs in $3.7-8 \%$ of the fistulas ${ }^{14,19,25,30,34}$. In the brachiocephalic and brachiobasilic fistulas it even appears in as much as $10-25 \%{ }^{19}$. Its manifestations include cold sensation and pallor of the limb, pain while working or during dialysis, sensitivity loss, cramps and pain while resting, the development of ulcers, necrosis to tissue loss ${ }^{19,23}$. In certain cases, the problems are not caused by the steal syndrome but rather by ischemic monomelic neuropathy ${ }^{35,36}$.

It is a question how to examine a patient with a sclerotic arterial bed and diabetes prior to the autogenous fistula performance in order to correctly indicate elbow fistula and how to prevent the development of a hyperfunctional fistula with the steal syndrome. There is probably no imaging method to indicate the fistula type. There is also no demonstrable method to clearly determine, before or after the fistula performance, that the fistula will be hyperfunctional with steal demonstrations ${ }^{34,37}$. However, imaging can determine where the fistula should not to be attempted because the arterial or venous bed does not provide a solid basis for a satisfactory result. After creation of the fistula in elbow, it is necessary to monitor the patient and the fistula as well as any steal syndrome symptoms development.

It is not difficult to recognise the developed clinical manifestations of the steal syndrome after the AV fistula creation. Effort should mainly be made to recognise the early manifestations in order to treat the fistula in time. A number of methods are recommended: physical examination of the site $^{24}$, digital plethysmography of the arm periphery ${ }^{24,25,33}$, skin temperature monitoring ${ }^{24}$, periphery oxygenation measurement ${ }^{24}$, digital pressure measurements $^{37}$, vessel bundle flow rate assessment by colour duplex sonography ${ }^{33}$ or arteriography of the entire fistula bed with or without fistula compression ${ }^{25,33}$. The fistula flow rate, however, does not typically influence steal development. Its occurrence rather depends on the peripheral arterial bed and collateral circulation ${ }^{24,40}$. 
The main therapy principle is resolving the ischemia and maintaining the access. However, this principle may be difficult to fulfil, mainly in risk groups of patients. A number of methods have been described and evaluated regarding modification of the autogenous elbow fistula between the brachial artery and the subcutaneous upper extremity (arm) venous bed with steal manifestations and regarding the maintained functionality thereof.

Primarily, it is the procedure of distal revascularization-interval ligation (DRIL). In principle, this is a venous bypass from the brachial artery above the AV fistula anastomosis to the radial or ulnar artery with the subsequent ligation of the brachial artery below the AV anastomosis. The method was described by Schanzer ${ }^{39}$ and applied by other authors who describe positive results, i.e. the ischemic symptoms improved in 90-100\% while maintaining fistula patency in $80-100 \%^{22,25,33}$. In patients with a poor arterial bed in the elbow, the anastomosis on radial or ulnar artery may be technically impossible.

Another technique is the proximalisation of the arterial inflow. The principle of this method is to interrupt the AV fistula anastomosis, treat the venous stump and then insert the ePTFE graft subcutaneously between the axillary artery and the original vein over the elbow. A 4-5mm gauge prosthesis is used. Larger-lumen prostheses can be later used for cannulation. Compared with the DRIL procedure, the stem artery is not ligated. The problems receded $90 \%$ of cases, and the fistula operability at 1 year was $90 \%$ (ref. ${ }^{32}$ ).

In line with the contemporary literature, other methods can be considered obsolete. These include reducing the flow through the fistula by stitches, banding or clip ${ }^{33,41}$. The disadvantage of such methods is either an insufficient reduction of the flow and thus failure to remove steal or such a reduction of the flow as to cause thrombosis of the fistula. Another option is the insertion of a graft after the AV anastomosis disconnecting between the brachial artery and efferent vein in the forearm subcutis ${ }^{38}$.

In a number of instances, mainly in diabetic patients with severe ischemic changes in the extremity peripheries, the request for saving the fistula cannot be met, and the only possibility is ligation of the arteriovenous access. In such cases, it must be determined whether to attempt another fistula or to apt for placing long-term central vein catheters or ports.

\section{CONCLUSIONS}

It can be summarised that the autogenous fistula in the elbow between the brachial artery and the cephalic or basilic vein currently holds an irreplaceable position in providing access for haemodialysis and that it needs to be preferred to using a graft. Mainly in risk groups of patients (diabetes mellitus, advanced stages of atherosclerosis), the condition of the patients needs to be monitored, as well as the flow through the fistula due to the possible steal syndrome occurrence. Further fistula treatment must be provided in the event of steal syndrome manifestations.
Proximalisation of the arterial inflow appears to be the most suitable method. Another method is the DRIL procedure. Certain cases cannot be repaired, the fistula cannot be saved and has to be surgicaly closed.

\section{REFERENCES}

1. Brescia MJ, Cimino JE, Appel K, Hurwick BF. Chronic hemodialysis using venipuncture and a surgically created arteriovenous shunt. N Engl J Med 1966; 275:1089-1092

2. NKF-DOQI clinical practice guidelines for vascular access. Am J Kidney Dis 1997; 37 Suppl 1:150-191

3. Cascardo S, Acchiardo S, Beven EG et al. Proximal arteriovenous fistulae for hemodialysis when radial arteries are unavailable. Proc Eur Dial Transplant Assoc 1970; 7:42-46

4. Dagher F, Gelber R, Ramos E, Sadler J. The use of basilic vein and brachial artery as an AV fistula for long term hemodialysis. J Surg Res 1976; 20:373-376

5. Gracz KC, Ing TS, Soung LS et al. Proximal forearm fistula for maintenance dialysis. Kidney Int 1977; 11:71-74

6. Pisoni RL, Young EW, Dykstra DM et al. Vascular access use in Europe and in the United States: Results from the DOPPS. Kidney Int 2002; 61:305-316

7. Tokars JI, Miller ER, Alter MJ, Arduino MJ. National surveillance of dialysis-associated diseases in the United States, 1997. Semin Dial 2000; 13:75-85

8. Schwab SJ. Vascular access for hemodialysis. Kidney Int 1999; 55:2078-2090

9. Raju S. PTFE grafts for hemodialysis access. Ann Surg 1987; 206:266-673

10. Allon M, Bailey R, Ballard R et al. A multidisciplinary approach to hemodialysis access: Prospective evaluation. Kidney Int 1998; 53:473-479

11. Ascher E, Gade P, Hingorani A et al. Changes in the practise of angioaccess surgery: impact of dialysis outcome and quality initiave recommendations. J Vasc Surg 2000; 31:84-92

12. Allon M, Robbin M. Increasing arteriovenous fistulas in hemodialysis patients: Problems and solutions. Kidney International 2002; 62:1109-1124

13. Oliver JM, Mccan RL, Indridason OS, Butterly DW, Schwab SJ. Comparison of transposed brachiobasilic fistulas to upper arm grafts and brachiocephalis fistulas. Kidney International 2001; 60:1532-1539

14. Murphy GJ, Saunders R, Metcalfe M, Nicholson ML. Elbow fistulas using autogenous vein: patency rates and results of revision. Postgraduate Medical Journal 2002; 78:483-486

15. Fitzgerald JT, Schanzer A, McVicar JP et al. Upper arm arteriovenous fistula versus forearm looped arteriovenous graft for hemodialysis access: a comparative analysis. Ann Vasc Surg 2005; 19:843-850

16. Fitzgerald JT, Schanzer A, Chin AI et al. Outcomes of upper arm arteriovenous fistulas for maintenance hemodialysis access. Arch Surg 2004; 139:201-208

17. Hakaim AG, Nalbandian M, Scott T. Superior maturation and patency of primary brachiocephalic and transposed basilic vein arteriovenous fistulae in patients with diabetes. J Vasc Surg 1998; 27:154-157

18. Butterworth PC, Doughman TM, Wheatley TJ, Nicholson ML. Arteriovenous fistula using transposed basilic vein. Br J Surg 1998; 85:653-654

19. Tordoir JH, Dammers R, van der Sande FM. Upper extremity ischaemia and hemodialysis vascular access. Eur J Vasc Endovasc Surg 2004; 27:1-5

20. Ehsan O, Bhattacharya D, Darwish A, Al-Khaffaf H. „Extension technique": a modified technique for brachiocephalic fistula to prevent dialysis access-associated steal syndrome. Eur J Vasc Endovasc Surg 2005; 29:324-327

21. Jendrisak MD, Anderson CB. Vascular access in patients with arterial insufficienty. Construction of proximal bridge fistulae 
based on inflow from axillary branch arteries. Ann. Surg. 1990; 21:187-193.

22. Schanzer H, Skladany M, Haimov M. Treatment of angioaccessinduced ischemia by revascularization. J Vasc Surg 1992; 16:864866

23. Lazarides MK, Staramos DN, Kopadis G, Maltezos C., Tzilalis VD, Georgiadis GS. Onset of arterial steal following proximal angioaccess: immediate and delayed types. Nephrol. Dial Transplant 2003; $18: 2387-2390$

24. van Hoek F, Scheltinga MR, Kouwenberg I et al. Steal in hemodialysis patients depends on type of vascular access. Eur J Vasc Endovasc Surg 2006; 32:710-717

25. Knox RC, Berman SS, Hughes JD, Gentile AT, Mills JL. Distal revascularization-interval ligation: A durable and effective treatment for ischemic steal syndrome after hemodialysis access. J Vasc Surg 2002; 36:250-256

26. Morsy AH, Kulbaski M, Chen C, Isiklar H, Lumsden AB. Incidence and characteristic of patients with hand ischemia after a hemodialysis access procedure. J Surg Res 1998; 74:8-10

27. Yeager RA, Moneta GL, Edwards JM et al. Relationship of hemodialysis access to finger gangrene in patients wit end-stage renal disease. J Vasc Surg 2002; 36:245-249

28. Sessa $\mathrm{C}$, Pecher $\mathrm{M}$ et al. Critical hand ischemia after angioaccess surgery. Ann Vasc Surg 2000; 14:583-593

29. Murphy GJ, Nicholson ML. Autogenous elbow fistulas: the effect of diabetes mellitus on maturation, patency, and complication rates. Eur J Vasc Endovasc Surg 2002; 23:452-457

30. Wixon CL, Hughes JD, Mills JL. Understanding strategies for the treatment of ischemic steal syndrome after hemodialysis access. J Am Coll Surg 2000; 191:301-310
31. Tynan-Cuisinier GS, Berman SS. Strategies for predicting and treating access induced ischemic steal syndrome. Eur J Vasc Endovasc Surg 2006; 32:309-315

32. Zanow J, Kruger U, Schulz H. Proximalization of the arterial inflow. A new technique to treat access-related ischemia. J Vasc Surg 2006; 43:1216-1221

33. Berman SS, Gentile AT, Glickman MH et al. Distal revascularization-interval ligation for limb salvage and maintenanace of dialysis access in ischemic steal syndrome. J Vasc Surg 1997; 26:393-402

34. Goff CD, Sato DT, Bloch PH et al. Steal syndrome complicating hemodialysis access pocedures: can it be predicted? Ann Vasc Surg 2000; $14: 138-144$

35. Miles AM. Upper limb ischemia after vascular access surgery: differential diagnosis and management. Semin Dial 2000; 13:312315

36. Hye RJ, Wolf IG. Ischemic monomelic neuropathy: an underrecognized complication of hemodialysis access. Ann Vasc Surg 1994; 8:578-582

37. Papasavas PK, Reifsnyder T, Birdas TJ, Caushaj PF, Leers S. Prediction of arteriovenous access steal syndrome utilizing digital pressure measurements. Vasc Endovasc Surg 2003; 37:179-184

38. West JC, Evans RD, Kelley SE et al. Arterial insufficiency in hemodialysis access procedures:reconstruction by an interposition PTFE graft conduit. Am J Surg 1987; 153:300-301

39. Schanzer H, Schwartz M, Harrington E, Haimov M. Treatment of ischemia due to „steal“ by arteriovenous fistula with distal artery ligation and revascularization. J Vasc Surg 1988; 7:770-773

40. Barnes RW. Hemodynamics for the vascular surgeon. Arch Surg 1980; 115:216-223

41. DeCaprio JD, Valentine RJ, Kakish HB et al. Steal syndrome complicating hemodialysis access. Cardiovasc Surg 1997; 6:648-653 